Адрес статьи / To link this article: $\underline{\text { http://cat.ifmo.ru/ru/2018/v3-i4/147 }}$

\title{
Психологические характеристики киберспортсменов в избранной дисциплине компьютерного спорта
}

\author{
И.М. Богдановская, Н.Н. Королева, А.В. Привалов \\ Российский государственный педагогический университет им. А.И. Герцена, Россия \\ ibogdanovs@herzen.spb.ru, korolevanatalya@mail.ru, \\ art.priv.work@gmail.com
}

\begin{abstract}
Аннотация. В исследовании рассматривались психологические характеристики киберспортсменов: свойства нервной системы, мотивы киберспортивной деятельности, волевые качества личности, направленность личности в игровом процессе (коллективизминдивидуализм) и особенности принятия решений. Выбор этих характеристик был сделан на основании пилотажного исследования, в котором изучались мнения экспертов (профессиональных киберспортсменов) о психологических факторах успешности в данном виде спортивной деятельности. Выборка исследования включала 56 респондентов в возрасте от 17 до 29 лет (средний возраст - 22 года). Основную группу исследования составили 42 человека - участника киберспортивных игр, объединенные в 3 подгруппы по 14 человек в соответствии с дисциплинами компьютерного спорта, в которых соревнуются данные игроки (класс «Шутеры», класс «МОВА», класс «Файтинги»). Критерием для отбора респондентов являлось участие в киберспортивных турнирах, проходящих в off-line режиме. В число участников исследования вошли: экс-чемпионка России по дисциплине «Tekken Tag Tournament», рейтинговые участники международных соревнований, участники профессиональных киберспортивных команд, а также призёры соревнований различного уровня. В зависимости от вида компьютерной игры киберспортсмены различаются по частным свойствам нервной системы («сила тормозного процесса» и «инертность нервных процессов»), выраженности мотива «коллективистская направленность», по общему показателю воли и волевым качествам инициативность, энергичность, смелость и деловитость; на уровне тенденции представлены различия по частному свойству нервной системы «сила возбудительного процесса». Влияние игрового стажа проявляется в различиях по парным факторам темперамента S и $\mathrm{N}$ (снижается склонность к поведению типа $\mathrm{S}$ и увеличивается, к поведению типа N); влияние времени, уделяемого киберспорту, проявляется в различиях по волевым качествам ответственность, инициативность, энергичность; влияние успешности в киберспорте влияет на мотивацию и волевые качества киберспортсменов. На основе анализа эмпирических данных были составлены типологические портреты представителей трёх классов киберспортивных дисциплин («Шутеры», «МОВА» и «Файтинги»).
\end{abstract}

Ключевые слова: киберспорт, киберспортсмен, психологические характеристики 


\section{1. Исследования психологических характеристик участников киберспортивных игр}

Психологические особенности - это особенности проявления психических и психофизиологических свойств человека, выступающие с одной стороны критериями его индивидуальности, а с другой - основаниями для типологизации людей по сходству и различию [1]. Киберспорт чаще всего ассоциируется с интеллектуальными видами спорта, так как для участия в нем требуются такие когнитивные свойства как скорость реакции, избирательный сбор информации, её когнитивная обработка и принятие оригинального решения сообразно игровой ситуации. D. Himmelstein et al. [2] пишут о том, что киберспортсменам свойственны разносторонние познания о компьютерных играх, умение мыслить стратегически и принимать быстрые решения, способность адаптироваться к различным тактикам противника, избегать отвлекаемости, поддерживать должный уровень внимания. C.S. Green et al. [3] отмечают, что у участников киберспортивных игр улучшается пространственное внимание, снижается импульсивность как реагирование на нецелевые стимулы. L.M. Trick et al. [4] также выявили улучшение возможности отслеживания движущихся объектов в поле отвлекающих факторов. Chiappi et al. [5] обнаружили более высокую способность к многозадачности у участников игр в жанре action. В то же время, современные исследователи отмечают, что занятия киберспортом связаны не только с когнитивными характеристиками участников. Для успешной киберспортивной деятельности им необходим ряд личностных характеристик: способность к волевой саморегуляции (умение не думать о прошлых выступлениях и сосредоточиться на процессе актуальной игры), умение разделять игру и повседневную жизнь, конструктивно общаться со своими товарищами по команде, доверять своим навыкам, быть способными к индивидуальному и командному саморазвитию, проводить анализ самоэффективности, обладать навыками постановки целей различных типов (краткосрочных, долгосрочных, процессуальных).

Интересной проблемой всех компьютерных игр, включая киберспортивные, является идентификация геймеров со своим игровым персонажем, образование синтеза физического и «игрового тела».D. Hemphill [6] отмечает, что в некоторых случаях различие между геймером и игровым персонажем как бы исчезает, или сливается с живым опытом. Современные киберспортивные игры разработаны таким образом, что интеллектуальное и эмоциональное погружение в них сопоставимо с переживаниями, которые встречаются в традиционных видах спорта. Для киберспортсменов эта особенность в сочетании с мотивацией конкуренции и достижения, ставит вопрос об индивидуально-типологических характеристиках геймеров.

В нашем исследовании, с целью выявления психологических особенностей участников киберспортивных игр, мы рассматривали такие характеристики как: свойства нервной системы, мотивы киберспортивной деятельности, волевые качества личности, направленность личности в игровом процессе (коллективизм-индивидуализм) и особенности принятия решений. Выбор для исследования именно этих характеристик был сделан на основании проведенного нами пилотажного исследования, в котором изучались мнения экспертов (профессиональных киберспортсменов) о психологических факторах успешности в данном виде спортивной деятельности. В исследовании были задействованы 14 киберспортсменов, активно принимающих участие в соревнованиях различного уровня (от дружеских до международных, среднегрупповой процент выигрышей 56,5\%). В качестве метода исследования использовалась авторская анкета, в содержание которой включались открытые и закрытые вопросы, направленные на уточнение психологических особенностей киберспортсменов. Полученные ответы оказались близки к результатам опроса о значимых психологических факторах в спорте, который проводили D.Railsback и N. Caporusso [7] среди традиционных и киберспортсменов. Исследователями была получена следующая ранговая последовательность психологических характеристик, значимых для киберспорта: способность к высокой концентрации внимания, критическое мышление, преданность игре, вовлеченность, постоянная практика, физические способности. В нашем исследовании опрошенные киберспортсмены указали на такие важные в этой деятельности психологические качества как: волевые (самоконтроль, целеустремлённость, настойчивость $(56,8 \%)$, уверенность в себе $(14,2 \%)$. С практически равной частотой эксперты признали значимость познавательного интереса, высокую скорость обработки информации, низкий порог реакции на стимул, быстрое принятие решений, высокая скорость реакции, коллективизм и доверие в случае командной игры.

Культура и технологии, Том 3, № 4 
Рассмотрим ряд современных исследований, посвящённых изучению этих психологических свойств у киберспортсменов.

\section{1. Исследование свойств нервной системы у киберспортсменов}

В немногочисленных работах представлены данные об эмоциональных характеристиках и свойствах нервной системы участников киберспортивных игр. По результатам исследования И.В. Стрельниковой, Г.В. Стрельниковой [8], профессиональные киберспортсмены проявляют высокую эмоциональную устойчивость в процессе соревнований, которая связана с активацией парасимпатического механизма регуляции. Н.А. Симоновой и Н.П. Петрушкиной [9] в связи с изучением проблемы нетрадиционных методов развития тактического мышления хоккеистов было выявлено влияние компьютерной игры Dota 2 на функциональное состояние нервной системы хоккеистов. Показано, что 30-минутная игра повышает возбудимость, подвижность, уравновешенность, внимание участников, а после 60 мин., баланс возбуждения-торможения смещается в сторону возбуждения. Этот результат представляется нам дискуссионным, так как особенности свойства нервной системы - это врождённые и генетически предопределённые характеристики, и возможность их устойчивого изменения в процессе какой-либо деятельности не получила достаточных научных доказательств. Имеет место определённая вариативность в их проявлении, в зависимости от продолжительности и интенсивности деятельности, но она имеет нормативные пределы для каждого конкретного человека. Именно эти изменения, скорее всего, и фиксируются исследователями, но трактуются ими как факт улучшения свойств нервной системы.

\section{2. Мотивация, мотивы и направленность личности у киберспортсменов}

В составе личностных характеристик киберспортсменов важное место занимает мотивация, обладающая по мнению F. Bányai et al. [10] общими характеристиками, несмотря на разнообразие и вариативность компьютерных игр. Так, среди мотивов обращения к компьютерному спорту N. Yeе [11] выделяет: мотивы достижения (самопродвижение, конкуренция), социальные мотивы (социализация, отношения, командная работа) и мотивы «погружения» (открытие нового, кастомизация, эскапизм). Отечественные исследователи $[12,13]$ дополняют спектр мотивов такими их группами как стремление к интеллектуальному удовольствию, эстетизм, творчество, самовыражение, а также внеигровые мотивы: рекреация, способ структурирования времени, развлечение. Однако, несмотря на довольно большое число исследований мотивации участников компьютерных игр, лишь в немногих из них рассматривалась мотивация профессиональных киберспортсменов. Bányai et al. [10] отмечают, что для профессионалов в отличие от любителей наиболее характерна мотивация достижения, в частности высокая конкурентоспособность.

Направленность личности участников компьютерных игр рассматривалась в работе А.А. Юркова [14], посвященной типологизации пользователей онлайн-игр. Исследуя мотивы игроков в онлайн-игры, учёный одним из факторов мотивации пользователей указывает социальный. Данный фактор выражается в стремлении к социализации, дружбе и командной работе, что указывает на коллективистскую направленность у некоторых участников онлайн-игр. Можно предположить, что такая направленность характерна для пользователей игр, подразумевающих необходимость активного командного взаимодействия для решения игровых задач.

\section{3. Волевые качества киберспортсменов}

Спортивная деятельность отличается тем, что её участникам периодически приходится преодолевать различные внешние и внутренние трудности, преодолевать себя для достижения поставленных целей и высоких результатов, длительное время работать на пределе физических и психических возможностей. Различные аспекты деятельности спортсмена непосредственно связанны с волевой регуляцией как способом самоуправления, так как требуют привлечения волевого усилия для преодоления препятствий. Именно так - в узком смысле - склонны понимать волю спортсмены и тренеры, обозначая её как «силу воли». Значение «силы воли» для достижения успехов в спорте подчёркивают многие спортивные деятели, что отражено в работах

International Culture \& Technology Studies, Vol. 3, No. 4 
по психологии спорта $[15,16]$. Одним из направлений изучения волевой сферы личности в спорте является исследование уровня выраженности тех или иных волевых качеств, а также общей способности к волевой регуляции как у представителей различных видов спорта (при сравнительных исследованиях), так и у спортсменов в целом. Наибольший интерес для нашего исследования представляла работа Ф. Генова [17], который пришёл к выводу о различном значении одних и тех же волевых качеств в разных видах спорта. Исходя из этой теории, он разделил все виды спорта на пять групп, для каждой из которых выделил по три группы волевых качеств, различающихся по уровням значимости для данных видов спорта: «ведущие», «ближайшие к ведущим» и «следующие за ними». Мы обратили своё внимание на четвёртую группу видов спорта, которая обозначаете как «спортивные игры», и на пятую, включающую в себя борьбу, бокс и фехтование. В качестве ведущих волевых качеств для спортивных игр $\Phi$. Генов указывает инициативность и самостоятельность, в качестве ближайших к ведущим настойчивость, решительность, смелость, и в качестве следующих за ними - самообладание, стойкость. Для бокса, борьбы и фехтования: ведущие - инициативность и самостоятельность, ближайшие к ведущим - решительность, смелось, следующие за ними — настойчивость, самообладание, стойкость.

В киберпсихологии воля освещается либо в рамках проблематики компьютерной игровой зависимости, либо в рамках проблем педагогики и развития личности. Так, А.В. Гришина [18-20] показано, что проблемное использование интернета связано у подростков со снижением таких характеристик волевой саморегуляции как способность к способности к постановке целей и планирование деятельности. Н.Н. Чебыкина [21] напротив, указывает на то, что компьютерные игры способствуют формированию волевых качеств личности.

\section{4. Индивидуально-типологические особенности киберспортсменов}

Индивидуально-типологические свойства киберспортсменов фактически не изучены в современной психологии, в то время как в традиционной психологии спорта эта проблема выступает одной из ключевых. Так, Е.В. Стрельниковой [22] установлено, что у киберспортсменов, предпочитающих такие игры, как «Dota 2» и «World of Tanks», скорость простой и сложной зрительно-моторной реакции, и реакции на движущийся объект значимо выше, чем у людей, не занимающихся киберспортом. Отдельные исследования посвящены анализу когнитивных характеристик участников киберспортивных игр. Проблеме когнитивных стилей у геймеров в посвящены работы Н.В. Богачевой [23, 24]. В них демонстрируются связи между когнитивными стилями геймеров (импульсивность-рефлективность и полезависимостьполенезависимость) и такими их особенностями как уровень игровой активности и предпочитаемый тип игр. Так геймеры, посвящающие игре более 12 часов в неделю, отличаются поленезависимым стилем, а менее 12 часов — рефлексивным. В работе А.А. Аветисовой [25] указывается на способность геймеров к быстрому принятию решений в ситуации неопределённости без потери точности и качества (правильности) принимаемого решения. По данным D.A. Lieberman [26], геймеры обладают развитыми навыками оперирования с информацией, планирования деятельности, постановки и проверки гипотез, принятия решений.

\section{2. Результаты эмпирического исследования психологических особенностей киберспортсменов}

В проведенном нами эмпирическом исследовании приняли участие 56 респондентов в возрасте от 17 до 29 лет (средний возраст составил 22 года). Основную группу исследования составили 42 человека - участника киберспортивных игр, объединены в 3 подгруппы по 14 человек в соответствии с классами киберспортивных игр, в которых соревнуются данные игроки (класс «Шутеры», класс «МОВА», класс «Файтинги»). Критерием для отбора респондентов являлось участие в киберспортивных турнирах, проходящих в off-line режиме. Данный критерий отражает уровень вовлеченности в занятия киберспортом и позволяет сформировать репрезентативную выборку. В число участников исследования вошли: экс-чемпионка России по дисциплине «Tekken Tag Tournament», рейтинговые участники международных соревнований, участники профессиональных киберспортивных команд, а также призёры соревнований 
различного уровня. Распределение участников по дисциплинам в рамках классов представлено в таблице 1.

Для сравнения была привлечена контрольная группа из 14 человек, не занимающихся киберспортом, уравненная с основной группой по половозрастным характеристикам.

Таблица 1. Распределение участников экспериментальной группы по избранным дисциплинам киберспорта

\begin{tabular}{|c|c|c|}
\hline Класс & Дисциплина & Кол-во участников \\
\hline \multirow[t]{3}{*}{ Шутеры (командные) } & Counter-Strike: Global Offensive & 12 \\
\hline & Counter-Strike 1.6 & 1 \\
\hline & Overwatch & 1 \\
\hline \multirow[t]{2}{*}{ MOBA } & Dota2 & 12 \\
\hline & League of Legends & 2 \\
\hline \multirow[t]{6}{*}{ Файтинги } & Guilty Gear Xrd Revelator & 7 \\
\hline & Street Fighter V & 2 \\
\hline & Tekken Tag Tournament 2 & 2 \\
\hline & Soul Calibur 5 & 1 \\
\hline & Ultra Street Fighter IV & 1 \\
\hline & The King of Fighters XIV & 1 \\
\hline
\end{tabular}

Исследование проводилось посредством психодиагностических и опросных методов (анкетирование). Диагностический комплекс включал в себя следующие методики: разработанная нами анкета для выявления демографических, ценностно-смысловых, мотивационных и коммуникативных особенностей участников киберспортивных игр; индивидуальнотипологический опросник (ИТПО) О. Ю. Гроголевой [27]; опросник диагностики темперамента Дж. Кейрси [28]; методика «Изучение мотивов занятия киберспортом» (авторская модификация методики «Изучение мотивов занятий спортом» В.И. Тропникова) [28]; методика исследования самооценки волевых качеств «Формализованная модификация методики самооценки (СО) ДембоРубинштейн» (В.А. Иванников, Е.В. Эйдман) [29]. В исследовании применялись следующие методы математико-статистической обработки данных. Дисперсионный анализ ANOVA для независимых выборок для выявления достоверно значимых различий в проявлениях индивидуально-типологических свойств участников различных киберспортивных игр и лиц, не занимающихся киберспортом. С целью установления связей между показателями, полученными в ходе эмпирического исследования, рассчитывался коэффициент линейной корреляции Пирсона. Для установления частоты встречаемости психологических типов использовался анализ частотных распределений признаков.

Предварительное анкетирование позволило уточнить некоторые характеристики киберспортивной деятельности: среднегрупповое время, уделяемое киберспорту (КС) в неделю составляет более 10 часов; среднегрупповая сумма материальных затрат на занятия КС в год: от 5 до 10 тыс. рублей; среднегрупповой процент выигрышей составляет 56,50\%. Несколько пунктов анкеты были направлены на выявление признаков чрезмерной увлеченности киберспортивными играми в таких направлениях как: 1) субъективные представления о невозможности отказа от КС игр; 2) пренебрежение другими делами; 3) изменения в эмоциональной и коммуникативной сферах; 4) отношение родителей и близких друзей.

Было установлено, что киберспортсмены не склонны негативно переживать отсутствие возможности принять участие в КС играх. Ответы на вопрос о переживаниях, возникающих при отсутствии возможности принять участие в КС играх распределились следующим образом: «никогда не испытываю» - 42,86\%, «испытываю» и «иногда испытываю» - по 28,57\%.Лишь $14,29 \%$ участников регулярно испытывают ощущение скуки и бессмысленности жизни без КС; $64,38 \%$ игроков такие ощущения переживают периодически, что в целом характерно для увлечённых людей. Примерно 50,00\% участников пренебрегают важными делами из-за увлечения КС, а среднегрупповой показатель по шкале, отражающей частоту, с которой из-за увлечения КС страдает успешность в иных сферах жизни $-2,57$ балла (при $\min =1$ и $\max =7$ баллам). Ответы на

International Culture \& Technology Studies, Vol. 3, No. 4 
вопрос о том, как увлечение КС повлияло на жизнь респондентов, распределились следующим образом: «негативно» $(7,14 \%)$, «нейтрально» $(50,00 \%)$, положительно $(35,71 \%)$. Друзья и родные в основном положительно относятся к увлечению киберспортом, что нехарактерно для случаев аддикции. По мнению опрошенных, данный вид деятельности способствует повышению настроения, на это указывают 78,57\% участников.57,14\% участников заявило, что занятие КС помогает справляться с негативными психическими состояниями. В коммуникативной сфере киберспортсменов важное место занимает общение с коллегами по увлечению: 78,57\% опрошенных признали для себя важным общение с другими киберспортсменами. Такое распределение результатов может свидетельствовать о высокой значимости КС в жизни респондентов, однако не позволяет причислить увлечение КС к одному из видов игровой аддикции.

С целью изучения индивидуально-типологических особенностей нервной системы (НС) киберспортсменов была проанализирована частота проявления таких ее частных свойств как сила и слабость возбудительного процесса, сила тормозного процесса, подвижность и инертность нервных процессов (НП).

В группе киберспортсменов класса «Шутеры» 78,57\% участников имеют сильную нервную систему, у 92,86\% киберспортсменов присутствует баланс между процессами возбуждения и торможения, у $71,43 \%$ участников исследования можно диагностировать высокую степень подвижности нервных процессов возбуждения и торможения.

В группе киберспортсменов класса «МОВА» $50 \%$ респондентов имеют сильную нервную систему, $35,71 \%$ средне-сильный тип НС, для 78,57\% киберспортсменов можно говорить о уравновешенности процессов возбуждения и торможения, $57,14 \%$ участников группы имеют подвижную нервную систему, однако довольно высок среди них и процент лиц со средним уровнем подвижности нервных процессов $(42,86 \%)$.

В группе киберспортсменов класса «Файтинги» выделяются следующие преобладающие типы НС: средняя НC $(35,71 \%)$, сильная НC $(28,57 \%)$, средне-слабая НC $(21,43)$. По свойству баланса возбуждения-торможения $85,71 \%$ участников имеют сбалансированный тип НС. Около $50 \%$ участников группы имеют среднюю подвижность НП, доля участники исследования с подвижным типом НС составляет $35,71 \%$.

В целом, в группе киберспортсменов преобладают лица с сильным типом НС (52,38\%), доля лиц со средней по силе $\mathrm{HC}-28,57 \%$. Согласно частотному распределению, в группе киберспортсменов преобладают лица с уравновешенной $\mathrm{HC}(85,71 \%)$, у большинства киберспортсменов отмечается высокоподвижная $(54,76 \%)$ и средне-подвижная $\mathrm{HC}(42,86 \%)$.

В контрольной группе по данным частотного распределения $42,86 \%$ участников имеет сильную $\mathrm{HC}$, следом за ними в $78,57 \%$ участников имеют уравновешенную $\mathrm{HC}$, доля лиц со средне-подвижной НС составляете $42,86 \%$, в то время как доля лиц с подвижной $\mathrm{HC}-50 \%$.

Дальнейшее исследование индивидуально-типологических особенностей позволило уточнить выраженность шести психологических факторов темперамента: сенсорика, интуиция, логичность, чувствование, решение, восприятие, а также функциональные портреты киберспортсменов.

Так, по шкалам сенсорика-интуиция (S-N) и «логичность-чувствование» (T-F) во всех исследуемых группах преобладающую долю составляют S-индивиды (сенсорики - 66,67\%) и Т-индивиды (логики - 71,43 \%). При этом, во всех группах среднегрупповые оценки S-N $(10,14 / 9,86)$ и T-F $(11,07 / 8,93)$ факторов темперамента различаются незначительно. По шкале «планирование-импульсивность» (Ј-Р) доля Ј-индивидов (планомерных $-85,71 \%$ ) во всех группах существенно превосходит долю Р-индивидов (импульсивных - 14, 29\%). При этом в каждой группе имеется высокая разница между среднегрупповыми оценками $\mathrm{J}$ и $\mathrm{P}$ факторов $(12,9 / 7,1$ - более чем на 3 балла). Это указывает на явное доминирование у участников группы форм поведения J-типа, проявляющегося в составлении чёткого плана действий и последовательного исполнения его отдельных этапов.

Доминирующими типами темперамента во всех исследуемых группах выступает «Эпиметей» (SJ-тип - 57,14\%), следом за ним неизменно идёт «Прометей» (NT-тип - 21, 43\%).

Культура и технологии, Том 3, № 4 
Представители SJ-типа - разумные конформисты, они деловиты, серьёзны и рассудительны в деятельности склонны к порядку, организованности и завершённости, ответственно подходят к работе и общению, воспринимая их как своего рода обязанности. Представители NT-типа - это мыслители-теоретики: они уверены в себе, не склонны ориентироваться на внешние критерии, однако их самооценка часто неустойчива; в общении они скрытны и низко эмоциональны, их поведение отличается нестандартностью и рискованностью.

Индивидуально-типологические особенности волевой сферы личности киберспортсменов изучались при помощи методики «Формализованная модификация методики самооценки (CO) Дембо-Рубинштейн» В.А. Иванникова, Е В. Эйдмана.

В классе «Шутеры» общий показатель воли и все оцениваемые волевые характеристики высоко выражены. Первостепенными выступают такие качества как: ответственность $(4,43)$ внимательность $(4,43)$ и целеустремлённость $(4,29)$. Близкими к первостепенным - спокойствие $(3,71)$, дисциплинированность $(3,64)$ и деловитость $(3,57)$.

В классе «МОВА» профиль в целом несколько снижен по сравнению с классом «Шутеры».Доминирующие волевые качества - целеустремлённость $(4,07)$ и принципиальность $(4,21)$, близкие к основным -дисциплинированность $(3,43)$, деловитость $(3,43)$, обязательность $(3,43)$, терпение $(3,36)$ и настойчивость $(3,36)$.

Волевой профиль класса «Файтинги» является более неоднородным, в котором наиболее чётко выделяются преобладающие и второстепенные волевые качества. К преобладающим относятся: принципиальность» $(4,07)$, ответственность $(3,93)$, целеустремлённость $(3,93)$, обязательность $(3,93)$, упорство $(3,86)$, спокойствие $(3,86)$; к второстепенным - инициативность $(3,07)$, смелость $(3,07)$, энергичность $(3,00)$, деловитость $(2,71)$.

У респондентов, не увлекающихся КС преобладающими волевыми качествами являются ответственность $(4,21)$, спокойствие $(4,21)$ целеустремлённость $(4,00)$ и терпеливость $(4,00)$; наименьшую выраженность имеют такие волевые качества как настойчивость $(3,14)$ и инициативность $(3,21)$.

Мотивы участия в КС играх и направленность личности по критерию индивидуализмколлективизм рассматривались с помощью авторской методики «Изучение мотивов занятия киберспортом». Респондентам предлагалось по 5-ти балльной шкале оценить у себя выраженность тех или иных мотивов занятия киберспортом.

В классе «Шутеры» наиболее высокие показатели имеют мотивы: «поиск острых ощущений» $(4,31)$, «коллективизм» $(4,15)$, «развитие характера и психических качеств» $(4,07)$, «потребность в одобрении» $(4,00)$, «эстетическое удовольствие» $(3,93)$, «индивидуализм» $(3,93)$, «творчество» $(3,88)$.В классе «МОВА» наиболее выражены такие мотивы как: «коллективизм» $(4,09)$, «творчество» $(3,99)$, «индивидуализм $(3,93)$, «потребность в одобрении» $(3,91)$, «эстетическое удовольствие» $(3,80)$. В классе «Файтинги» явно выделяются такие доминирующие мотивы как «эстетическое удовольствие» $(4,19)$, «индивидуализм» $(4,11)$, «развитие характера и психических качеств» $(4,07)$, «поиск острых ощущений» $(3,97)$, «творчество» $(3,86)$.

Обращаясь к вопросу направленности личности по основанию коллективизминдивидуализм, можно видеть, что коллективистская направленность преобладает у представителей классов «Шутеры» $(4,15)$ и «МОВА» $(4,09)$, при этом уровень индивидуалистической направленности так же очень высок $(3,93$ в обоих классах). Индивидуалистическая направленность преобладает у представителей класса «Файтинги» $(4,11)$, что объясняется спецификой данного класса игр.

Для уточнения специфики проявления индивидуально-типологических характеристик киберспортсменов в зависимости от класса игр, был проведен дисперсионный анализ. Независимая переменная (класс киберспортивной игры) включала четыре градации: 1 - класс «Шутеры», 2 - класс «МОВА», 3 - класс «Файтинги», 4 - неиграющие участники исследования. Результаты анализа приведены в таблице 2.

Частные свойства «Сила возбудительного процесса» и «Слабость возбудительного процесса» следует рассматривать вместе, так как они оба принадлежат к одному общему свойству

International Culture \& Technology Studies, Vol. 3, No. 4 
сила-слабость НС. Среди киберспортсменов наибольшая среднегрупповая оценка по силе возбудительного процесса характеризует игроков в «Шутеры» $(3,82)$, им же принадлежит и самая низкая оценка по слабости $(2,18)$, что указывает на преобладание в группе лиц с сильным типом $\mathrm{HC}$, подтверждённое частотным распределением типов НС в данной группе. Различия по «Силе» между участниками классов «MOBA» $(3,54)$ и «Файтинги» $(3,45)$ не так велико, но значима дифференциация по «Слабости» $(2,57 / 3,11)$. Респонденты, не имеющие опыта киберспортивных игр, характеризуются самыми низкими оценками по обоим свойствам $(3,40 / 2,77)$. Присутствие различий по данным частным свойствам $\mathrm{HC}$, указывает и на различия по её общему свойству «сила-слабость». При этом частные свойства «силы» и «слабости» должны вносить примерно равный вклад в различия по соответствующему общему свойству.

Таблица 2. Проявления индивидуально-типологических характеристик киберспортсменов в зависимости от класса игр (результаты дисперсионного анализа, $\mathrm{N}=56$ )

\begin{tabular}{|c|c|c|c|c|c|}
\hline Показатель & «Шутеры» & MOBA» & «Файтинги» & Неиграющие & $\begin{array}{c}\text { Уровень } \\
\text { доверительной } \\
\text { вероятности р < }\end{array}$ \\
\hline \multicolumn{6}{|c|}{ Частные свойства НС } \\
\hline $\begin{array}{l}\text { Сила возбудительного } \\
\text { процесса }\end{array}$ & 3,83 & 3,54 & 3,45 & 3,40 & 0,08 \\
\hline $\begin{array}{l}\text { Слабость возбудительного } \\
\text { процесса }\end{array}$ & 2,18 & 2,51 & 3,11 & 2,77 & 0,001 \\
\hline Инертность НП & 2,11 & 2,48 & 2,84 & 2,75 & 0,02 \\
\hline \multicolumn{6}{|c|}{ Мотивы занятия КС } \\
\hline Общение & 3,13 & 3,11 & 2,56 & & 0,09 \\
\hline Острые ощущения & 4,31 & 3,71 & 3,97 & & 0,08 \\
\hline $\begin{array}{l}\text { Коллективистическая } \\
\text { направленность }\end{array}$ & 4,15 & 4,09 & 3,03 & & 0,001 \\
\hline \multicolumn{6}{|c|}{ Волевые качества личности } \\
\hline Воля & 4,21 & 3,86 & 3,07 & 3,64 & 0,01 \\
\hline Инициативность & 4,00 & 3,71 & 3,07 & 3,21 & 0,02 \\
\hline Энергичность & 3,93 & 3,86 & 3,00 & 3,50 & 0,01 \\
\hline Смелость & 4,14 & 3,7 & 3,07 & 3,64 & 0,001 \\
\hline Деловитость & 3,57 & 3,43 & 2,71 & 3,85 & 0,001 \\
\hline
\end{tabular}

Другое частное свойство НС, по которому были установлены достоверно значимые различия - инертность нервных процессов. Наибольшую среднегрупповую оценку по этому свойству имеет класс «Файтинги» $(2,84)$, за ним идёт «МОВА» $(2,48)$, и завершают «Шутеры» $(2,11)$. Лица, не занимающиеся КС, имеют средние оценки $(2,75)$. Различия по данному частному свойству НС, указывает и на различия по её общему свойству «подвижность-инертность нервных процессов». При этом различия между спортсменами разных классов по свойству «подвижностиинертности» будет определяться главным образом за счёт «инертности».

В отношении мотивов участия в КС хорошо заметна схожесть разброса средних по мотивам «Коллективизм» и «Общение» в разных группах: оба мотива практически не различаются и имеют высокие среднегрупповые значения в классах «Шутеры» и «МОВА» («Общение» $3,13 / 3,11$; «Коллективизм» - 4,15/4,09). Значимо отличаются от них оценки класса «Файтинги» («Общение» - 2,56, «Коллективизм»-3,03), что объясняется индивидуальным типом ведения игры в этом классе.

Волевые качества имеют наибольшую выраженность в классе «Шутеры», среднюю в классе «МОВА» и низкую в классе «Файтинги». Эта закономерность подкрепляется и схожим убыванием общего показателя силы воли, обуславливающего выраженность самооценки всех волевых качеств. Среднегрупповые оценки по всем названным качествам у лиц, не занимающихся КС, находятся между оценками классов «МОВА» и «Файтинги», из чего следует, что класс «Файтинги» составляют лица с наименее выраженными волевыми характеристиками.

Культура и технологии, Том 3, № 4 
С целью установления взаимосвязей между индивидуально-типологическими свойствами киберспортсменов и характеристиками КС деятельности нами был проведён внутригрупповой анализ линейной корреляции для трёх групп участников, соответствующих классам киберспортивных игр.

В классе «Шутеры» выявлена обратная взаимосвязь стажа занятия киберспортивной деятельностью с таким мотивом участия в игре как «развитие характера и психологических качеств» $(\mathrm{r}=-0,67, \mathrm{p}=0,01)$. Возможно, по мере занятия КС, ведущие мотивы спортсменов сменяют друг друга с течением времени. Время, уделяемое КС, положительно взаимосвязано с волевым качеством «внимательность» $(\mathrm{r}=0,64, \mathrm{p}=0,1)$. Успешность КС деятельности в классе «Шутеры» наиболее тесно взаимосвязана с такими качествами личности как смелость $(\mathrm{r}=0,57, \mathrm{p}=0,052)$, решительность $(\mathrm{r}=0,67, \mathrm{p}=0,01)$ и уверенность $(\mathrm{r}=0,68, \mathrm{p}=0,009)$.

В классе «МОВА» стаж занятия КС обнаруживает положительную взаимосвязь с самооценкой «энергичности» $(\mathrm{r}=0,67, \mathrm{p}=0,01)$ и инициативности $(\mathrm{r}=0,54, \mathrm{p}=0,05)$, а также мотивами КС деятельности «общение» $(\mathrm{r}=0,62, \mathrm{p}=0,02)$ и «потребность в одобрении» $(\mathrm{r}=0,55$, $\mathrm{p}=0,04)$. Время уделяемое КС отрицательно взаимосвязано с самооценкой «смелости» $(\mathrm{r}=-0,51$, $\mathrm{p}=0,05)$ и положительно - с самооценкой «инициативности» $(\mathrm{r}=0,49, \mathrm{p}=0,05)$. Предположительно, для участников класса «МОВА» занятие КС может иметь компенсаторный смысл, предоставляя возможность в безопасных условиях реализовать стремление к острым ощущениям, которое называлось в качестве одного из ведущих мотивов КС, реализовать свой творческий потенциал, получить одобрение и признание.

В классе «Файтинги» выявлена взаимосвязь стажа занятий КС с N-фактором темперамента (интуиция) $(\mathrm{r}=0,77, \mathrm{p}=0,001)$. Положительная взаимосвязь стажа занятия КС с самооценками «упорства» $(\mathrm{r}=0,56, \mathrm{p}=0,04)$ и «принципиальности» $(\mathrm{r}=0,54, \mathrm{p}=0,05)$ позволяет предположить, что игра служит развитию этих качеств. Время уделяемое КС взаимосвязано с F-фактором темперамента (чувствование) $(\mathrm{r}=0,55, \mathrm{p}=0,04)$.

На основании сведений, полученных после анализа данных проведённого исследования, нами были составлены типологические портреты представителей трёх классов киберспортивных игр: «Шутеры», «МОВА» и «Файтинги» (таблица 3).

В начале хотелось бы отметить те индивидуально-типологические свойства, особенности проявления которых схожи у участников всех представленных классов. Ими являются факторы темперамента, обуславливающие особенности когнитивной сферы киберспортсменов.

Обобщённый типологический портрет киберспортсмена класса «Шутеры» выглядит следующим образом: это индивид с сильной, уравновешенной НС средней подвижности. Такой тип НС в целом соответствует условиям данного класса игр, в которых отдельные раунды длятся в пределах нескольких минут, а соревновательная ситуация протекает обычно в одном ритме. Из нескольких таких раундов с небольшими перерывами складывается матч. От спортсмена требуется максимальное включение всех ресурсов на непродолжительное время раунда, после чего он может на короткий период расслабиться и так же мобилизовать себя в следующем раунде. Высокая сила и средняя подвижность обеспечивают адекватную деятельность спортсмена при описанном режиме игры. В качестве ведущих волевых качеств данного класса спортсмены указывают ответственность, внимательность, целеустремлённость, а второстепенных спокойствие, дисциплинированность и деловитость. По результатам проведенного корреляционного анализа, можно говорить о том, что успешность в КС деятельности обеспечивается, главным образом, за счёт таких качеств личности как смелость, решительность и уверенность.У представителей класса «Шутеры» командного вида коллективистская направленность превалирует над индивидуалистической, что соответствует схожим результатам у представителей командных видов в традиционном спорте. Вместе с тем индивидуалистическая направленность в данном классе так же очень высока, что может указывать как на личную заинтересованность спортсмена в победе команды, так и на принятие на себя ответственности за общий успех. 
Таблица 3. Типологические портреты участников КС игр

\begin{tabular}{|c|c|c|c|}
\hline \multirow{2}{*}{$\begin{array}{l}\text { Индивидуально- } \\
\text { типологические } \\
\text { свойства } \\
\end{array}$} & Класс «Шутеры» & Класс «МОВА» & Класс «Файтинги» \\
\hline & \multicolumn{3}{|c|}{ Индивидуально-типологические особенности } \\
\hline \multicolumn{4}{|c|}{ Свойства НС } \\
\hline Сила-слабость НС & Сильная & Сильная, реже средняя & $\begin{array}{l}\text { Средняя, реже сильная } \\
\text { или средне-слабая }\end{array}$ \\
\hline $\begin{array}{l}\text { Баланс возбуждения- } \\
\text { торможения НП }\end{array}$ & Уравновешенность & Уравновешенность & Уравновешенность \\
\hline $\begin{array}{l}\text { Подвижность- } \\
\text { инертность НП }\end{array}$ & Средняя подвижность & $\begin{array}{l}\text { Высокая подвижность, } \\
\text { реже средняя }\end{array}$ & $\begin{array}{l}\text { Средняя подвижность, } \\
\text { реже высокая }\end{array}$ \\
\hline \multicolumn{4}{|c|}{ Факторы темперамента (когнитивная сфера) } \\
\hline $\begin{array}{l}\text { Сенсорика-интуиция } \\
\text { (S-N) }\end{array}$ & $\begin{array}{l}\text { Некоторая склонность к } \\
\text { сенсорному типу }\end{array}$ & $\begin{array}{l}\text { Некоторая склонность к } \\
\text { сенсорному типу }\end{array}$ & $\begin{array}{l}\text { Некоторая склонность к } \\
\text { сенсорному типу }\end{array}$ \\
\hline $\begin{array}{l}\text { Логичность- } \\
\text { чувствование (T-F) }\end{array}$ & $\begin{array}{l}\text { Некоторая склонность к } \\
\text { логическому типу }\end{array}$ & $\begin{array}{l}\text { Некоторая склонность к } \\
\text { логическому типу }\end{array}$ & $\begin{array}{l}\text { Некоторая склонность к } \\
\text { логическому типу }\end{array}$ \\
\hline $\begin{array}{l}\text { Планирование- } \\
\text { иимпульсивность (J-P) }\end{array}$ & Планирующий тип & Планирующий тип & Планирующий тип \\
\hline $\begin{array}{l}\text { Тип темперамента по } \\
\text { Кейрси }\end{array}$ & «Эпиметей» (SJ-тип) & «Эпиметей» (SJ-тип) & «Эпиметей» (SJ-тип) \\
\hline \multicolumn{4}{|c|}{ Волевые качества личности } \\
\hline Общая показатель воли & Высокий & Выше среднего & Средний \\
\hline Доминирующие & $\begin{array}{l}\text { Ответственность, } \\
\text { внимательность, } \\
\text { целеустремленность }\end{array}$ & $\begin{array}{l}\text { Целеустремсть, } \\
\text { принципиальность }\end{array}$ & $\begin{array}{l}\text { Принципиальность, } \\
\text { ответственность, } \\
\text { целеустремленность, } \\
\text { обязательность, } \\
\text { упорство, спокойствие }\end{array}$ \\
\hline Второстепенные & $\begin{array}{l}\text { Спокойствие, } \\
\text { дисциплинированность, } \\
\text { деловитость }\end{array}$ & $\begin{array}{l}\text { Дисциплинированность, } \\
\text { деловитость, } \\
\text { обязательность, } \\
\text { терпение, } \\
\text { настойчивость }\end{array}$ & $\begin{array}{l}\text { Смелость } \\
\text { инициативность, } \\
\text { смелость, энергичность, } \\
\text { деловитость }\end{array}$ \\
\hline $\begin{array}{l}\text { Связанные с } \\
\text { успешностью в КС }\end{array}$ & $\begin{array}{l}\text { Смелость, } \\
\text { решительность }\end{array}$ & $\begin{array}{l}\text { Смелость, } \\
\text { настойчивость }\end{array}$ & Принципиальность \\
\hline \multicolumn{4}{|c|}{ Направленность личности } \\
\hline $\begin{array}{l}\text { Коллективизм- } \\
\text { индивидуализм }\end{array}$ & Коллективизм & Коллективизм & Индивидуализм \\
\hline \multicolumn{4}{|c|}{ Мотивационная сфера } \\
\hline $\begin{array}{l}\text { Основные мотивы } \\
\text { занятия КС }\end{array}$ & $\begin{array}{l}\text { Потребность в острых } \\
\text { ощущениях, и } \\
\text { индивидуализм } \\
\text { коллективистские } \\
\text { мотивы, развитие } \\
\text { характера и психических } \\
\text { качеств, потребность в } \\
\text { одобрении, эстетическое } \\
\text { удовольствие, } \\
\text { творчество }\end{array}$ & $\begin{array}{l}\text { Творчество, } \\
\text { потребность } \\
\text { одобрении, } \\
\text { эстетическое } \\
\text { удовольствие, } \\
\text { индивидуализм } \\
\text { коллективистские } \\
\text { мотивы }\end{array}$ & $\begin{array}{l}\text { Эстетическое } \\
\text { удовольствие, развитие } \\
\text { характера и психических } \\
\text { качеств, потребность в } \\
\text { острых ощущениях, } \\
\text { творчество, } \\
\text { индивидуалистические } \\
\text { мотивы }\end{array}$ \\
\hline
\end{tabular}

Обобщённый типологический портрет киберспортсмена класса «МОВА». Это индивиды с сильной, реже средней по силе, уравновешенной НС высокой или реже средней подвижности. Описанный тип НС в целом подходит для игр данного класса. Матчи здесь не делятся на раунды и длятся в среднем по 40 минут. Лица с сильным и средне-сильным типами НС достаточно выносливы, чтобы сохранять нужную активность на протяжении всего периода матча. Течение игрового процессе отличается неоднородностью, имеют место резкие смены игровых ситуацией. Высокая и средняя подвижность НП обеспечивает быстрою адаптацию к смене игровой ситуации. Доминирующие волевые качества — целеустремлённость и принципиальность; наименее выражены дисциплинированность, деловитость, обязательность, терпение, настойчивость. С успешностью в КС деятельности взаимосвязаны самооценки таких волевых качеств как смелость и 
настойчивость. Обращает на себя внимание, что именно самооценка настойчивости у спортсменов данного класса является самой низкой из всех оцениваемых волевых качеств. По-видимому, именно те респонденты, у которых настойчивость выражена сильнее, оказываются успешными в данном виде киберспорта и на него следует обращать особое внимание при развивающей работе со спортсменами данного класса.

Обобщённый типологический портрет киберспортсмена класса «Файтинги». По результатам проведенного исследования сила НС у представителей данного класса может быть, как средней, так и сильной, либо средне-слабой, игрокам присуща уравновешенность возбуждения и торможения и средняя или реже высокая подвижность НП. Такой разброс в отношении силы НС связан, на наш взгляд, с типом игры. Наиболее распространена следующая схема проведения соревнований: матч делится на три раунда, в каждом из которых проводятся три схватки. Время отдельной схватки обычно огранивается 1,5 минутой, но чащей бой заканчивается быстрее. Промежуток между схватками составляет 3 секунды. Промежуток между раундами несколько больше, и спортсмены могут немного перевести дух. Для лиц с сильной НС характерен высокий порог активации, т.е. они медленнее включаются в деятельность, поэтому при прочих равных условиях, скорее всего, будут более успешны во второй половине второго раунда и третьем раунде. Лица со средней по силе НС будут включаться несколько быстрее, иметь примерно равную успешность на протяжении всех раундов. У лиц со средне-слабой НС порог активации ещё более снижен, они будут ещё быстрее включаться, однако и быстрее достигнут предела активности, вследствие чего успешными для них будут скорее первый раунд и первая половина второго раунда. Средняя и высокая подвижность НП так же будут способствовать успешности. Специфика игры предполагает, как возможность реализовать разный стиль игры за одного и того же персонажа, так и свои неповторимые особенности у разных персонажей. При этом, на некоторых соревнованиях допускается смена персонажа между раундами. Отсюда следует, что спортсмен должен обладать высокой способностью к адаптации, так как противник может менять и стиль своей игры, и персонажа по ходу матча. Средний и высокий уровни подвижности НС способствует адаптивности в указанных ситуациях. Среднегрупповые показатели по волевым качествам в классе «Файтинги» ниже чем у представителей других классов. Доминирующими волевыми качествами выступают принципиальность, ответственность, целеустремленность, обязательность, упорство, спокойствие, а второстепенными - смелость инициативность, смелость, энергичность, деловитость. Успешность в КС деятельности обнаруживает взаимосвязь только с таким волевым качеством как принципиальность, влияние которого на успешность неочевидно. Индивидуалистическая направленность у представителей данного класса игр явно преобладает на коллективистской, что объясняется одиночным типом игры. Полученные результаты подтверждают гипотезу нашего исследования о специфике индивидуальнотипологических характеристик у представителей различных классов киберспортивных игр.

\section{Заключение}

В заключении следует отметить, что в отношении свойств НС нами не было обнаружено сходства типологических портретов представителей трёх классов КС игр с портретами представителей традиционных видов спорта $[1,16,28]$. Волевые качества, связанные с успешностью у участников разных классов КС игр, также не соотносятся с ведущими качествами у спортсменов, согласно исследованиям Ф. Генова [17]. Всё это указывает на высокую самобытность и своеобразие рассмотренных видов виртуального спорта и требует продолжения исследований индивидуально-типологических характеристик киберспортсменов.

\section{Литература}

[1] Ильин, Е.П. Психология индивидуальных различий / Е.П.Ильин. - СПб: Питер, 2004. - 701 с. - (Серия «Мастера психологии»)

[2] Himmelstein, D., Liu, Y., \& Shapiro, J. L. (2017). An exploration of mental skills among competitive League of Legend players. International Journal of Gaming and Computer-Mediated Simulations, 9(2), 1-21.

[3] Green C.S., Bavelier D. Learning, attentional control, and action video games. Curr Biol. 2012; 22(6): R197206.

[4] Trick, L. M., Jaspers-Fayer, F., Sethi, N. (2005). Multiple-object tracking in children: The "Catch the Spies" task. Cognitive Development, 20, 373-387.

International Culture \& Technology Studies, Vol. 3, No. 4 
[5] Dan Chiappe, Mark Conger, Janet Liao, J. Lynn Caldwell, Kim-Phuong L. Vu Corrigendum to 'Improving Multi-tasking Ability Through Action Videogames [JERG 44/2 (2013) 278-284] Applied Ergonomics, Volume 44, Issue 5, September 2013 p.850

[6] The Philosophy of Computer Games Conference, Madrid 2012 Cybersport 2.0: Ethical Dimensions of Videogames as Sport Sean Naubert, Hemphill, Dennis. "Cybersport."Journal of Philosophy of Sport 32 (2005) Human Kinetics Inc.:195-207.

[7] Railsback D., Caporusso N. (2019) Investigating the Human Factors in eSports Performance. In: Ahram T. (Eds) Advances in Human Factors in Wearable Technologies and Game Design. AHFE 2018. Advances in Intelligent Systems and Computing, vol 795. Springer, Cham

[8] Стрельникова И. В., Стрельникова Г. В. Психоэмоциональное состояние киберспортсменов перед соревнованием //Вопросы функциональной подготовки в спорте высших достижений. 2013. Т. 1. №. 1. C. $322-324$.

[9] Симонова Н. А., Петрушкина Н. П. Эффективность применения нетрадиционных методов улучшения свойств нервной системы у хоккеистов пубертатного возраста //Здоровье для всех. 2015. С. 325-328.

[10] Bányai, F., Griffiths, M.D., Király, O. et al. J Gambl Stud (2018). https://doi.org/10.1007/s10899-018-9763-1

[11] Nick Yee. CyberPsychology \& Behavior.Dec 2006. Ahead of print http://doi.org/10.1089/cpb.2006.9.772

[12] Макалатия А.Г. Мотивация в компьютерных играх // 3-я Российская конференция по экологической психологии (Москва, 15-17 сентября 2003 г.): тез. М. 2003. С.358-361.

[13] Фомичёва Ю.В., Шмелёв А.Г., Бурмистров И.В. Психологические корреляты увлечённости компьютерными играми // Вестник Московского университета. Серия 14: Психология. 1991. № 3. С. 27 39.

[14]Юрков, А.А. Типологизация пользователей онлайн-игр и их мотивация / А.А. Юрков // Знание. Понимание. Умение. - М: МосГУ, 2012. - №3. - С.301-304.

[15]Гогунов, Е.Н. Психология физического воспитания и спорта: Учеб. пособие для студ. выш. пед. учеб. заведений: / Е.Н.Гогунов, Б.И.Мартьянова. - 2-е изд., дораб. -М.: Издательский центр «Академия», 2004. $-224 \mathrm{c}$.

[16]Ильин, Е.П. Психология физического воспитания: Учебник для институтов и факультетов физической культуры: 2-е изд., испр. и доп. / Е.П.Ильин. - СПб: РГПУ им. А. И. Герцена, 2000. - 486 с.

[17]Генов, Ф. Психологические особенности мобилизационной готовности спортсмена / Ф. Генов. - М.: Физкультура и спорт, 1971. - 246 с.

[18]Гришина, А.В. Психологические факторы формирования игровой компьютерной зависимости в младшем подростковом возрасте / А.В.Гришина // Известия Российского государственного педагогического университета им. А.И. Герцена. - СПб: РГПУ им. А. И. Герцена, 2008 г. - №88. - С. 77 81.

[19] Смолл, Г. Мозг онлайн: Человек в эпоху Интернета / Г, Смолл, Г.Ворган. - М.: КоЛибри, $2011 .-352$ с.

[20] Khodakovskaia O.V., Bogdanovskaya I.M., Koroleva N.N., Alekhin A.N., Lugovaya V.F. (2018) Problematic Internet Usage and the Meaning-Based Regulation of Activity Among Adolescents. In: Alexandrov D., Boukhanovsky A., Chugunov A., Kabanov Y., Koltsova O. (eds) Digital Transformation and Global Society. DTGS 2018. Communications in Computer and Information Science, vol 859. Springer, Cham

[21]Чебыкина, Н.Н. Влияние компьютерных игр на человека / Н.Н.Чебыкина // Теория и практика профессионального образования: педагогический поиск: сборник научных трудов. - Екатеринбург, 2007. - Вып. 9. - С. 193-194.

[22] Стрельникова Г.В., Стрельникова И.В., Янкин Е.Л. Особенности сенсомоторной и когнитивной сфер киберспортсменов, выступающих в разных дисциплинах // Наука и спорта: современные тенденции. Казань: Поволжская гос. академия физической культуры, спорта и туризма, 2016. Т. 12, №3 (12). С. 6469.

[23][23] Богачева, Н.В. Компьютерные игры и психологическая специфика когнитивной сферы геймеров / Н.В.Богачева // Вестник Московского университета. Серия 14: Психология. - М.: Факультет психологии МГУ, 2014. - №4. - С. 120-130.

[24] Богачева, Н.В. Психология киберспорта как новое направление спортивной психологии / Н.В.Богачева, Д.В.Смит // Материалы VIII Международной научно-практической конференции «Рудиковские чтения» (5-7 июня 2012 г.). - М., 2012. - С. 12-15.

[25] Аветисова, А.А. Психологические особенности игроков в компьютерные игры / А.А.Аветисова // Психология. Журнал Высшей школы экономики. - М.: Национальный исследовательский университет «Высшая школа экономики», 2011. - Т. 8, № 4. - С.35-58.

[26]Lieberman D. A. What Can We Learn From Playing Interactive Games? // Playing video games: motives, responses, and consequences / Ed. by Vorderer P., Bryant J. Mahwah, NJ: LEA Publ.2006. P. 379-398.

[27]Гроголева О.Ю., Генералова А.В. Психологический практикум. Ощущение. Восприятие. Представление: Учебно-методическое пособие. Омск: Омск. гос. университет. 2004. 68 с.

[28]Ильин Е.П. Психология индивидуальных различий. Спб: Питер. 2004. 701 с.

[29]Иванников В.А., Эйдман В.А. Структура волевых качеств по данным самооценки.Психологический журнал. 1990. Т. 11. №3. С.39-40.

Культура и технологии, Том 3, № 4 


\title{
Individual and typological characteristics of participants in cybersport games
}

\author{
I.M. Bogdanovskaya, N.N. Koroleva, A.V. Privalov
}

Herzen State Pedagogical University of Russia

\begin{abstract}
The study examined the psychological characteristics of cybersportsmens: the properties of the nervous system, the motives of cybersport activity, the volitional qualities of the personality, the orientation of the personality in the game process (collectivism-individualism) and decision-making features. The choice of these characteristics based on a pilot study in which the opinions of experts (professional cybersportsmens) on psychological factors of success in this type of sports activity were studing. The sample of the study included 56 respondents aged from 17 to 29 years old (average age 22 years). The main group of research consisted of 42 people - a participant in e-sports games, united in 3 subgroups of 14 people in accordance with computer sports disciplines in which these players compete (class "Shooters", class "MOBA", class "Fighting"). The criterion for the selection of respondents was participation in e-sports tournaments held in off-line mode. The research participants included the ex-champion of Russia in the Tekken Tag Tournament discipline, rating participants in international competitions, participants in professional eSports teams, as well as prize-winner's at various levels of competitions. Depending on the type of computer game, cybersportsmens differ in particular properties of the nervous system ("the strength of the inhibitory process" and "inertness of nervous processes"), the severity of the motive "collectivist orientation", in terms of a general indicator of will and volitional qualities, initiative, energy, courage and efficiency.At the trend level, the differences in the particular property of the nervous system "the power of the excitatory process" are presenting. The influence of the playing experience is manifesting in differences in the pairing factors of temperament $\mathrm{S}$ and $\mathrm{N}$ (the tendency to the type $\mathrm{S}$ behavior decreases and increases to the type $\mathrm{N}$ behavior). The effect of time devoted to eSports is manifesting in differences in volitional qualities: responsibility, initiative, energy. The impact of success in eSports affects the motivation and volitional qualities of eSports. Based on the analysis of empirical data, typological portraits of representatives of three classes of eSports disciplines ("Shooters", "MOBA" and "Fighting's") were compiling.
\end{abstract}

Keywords: eSports, eSportsman, psychological profiles of the eSportsmans

\section{References}

[1] Il'in, E.P. Psihologiya individual'nyh razlichii [Psychology of individual differences]/ E.P.Il'in. SPb: Piter, 2004. 701 s. (Seriya «Mastera psihologii»)

[2] Himmelstein, D., Liu, Y., \& Shapiro, J. L. (2017). An exploration of mental skills among competitive League of Legend players. International Journal of Gaming and Computer-Mediated Simulations, 9(2), 1-21.

[3] Green C.S., Bavelier D. Learning, attentional control, and action video games. Curr Biol. 2012; 22(6): R197206.

[4] Trick, L. M., Jaspers-Fayer, F., Sethi, N. (2005). Multiple-object tracking in children: The Catch the Spies task. Cognitive Development, 20, 373-387.

[5] Dan Chiappe, Mark Conger, Janet Liao, J. Lynn Caldwell, Kim-Phuong L. Vu Corrigendum toImproving Multi-tasking Ability Through Action Videogames [JERG 44/2 (2013) 278-284] Applied Ergonomics, Volume 44, Issue 5, September 2013 p.850

[6] The Philosophy of Computer Games Conference, Madrid 2012 Cybersport 2.0: Ethical Dimensions of Videogames as Sport Sean Naubert, Hemphill, Dennis. "Cybersport."Journal of Philosophy of Sport 32 (2005) Human Kinetics Inc.:195-207.

[7] Railsback D., Caporusso N. (2019) Investigating the Human Factors in eSports Performance. In: Ahram T. (Eds) Advances in Human Factors in Wearable Technologies and Game Design. AHFE 2018. AdvancesinIntelligentSystemsandComputing, vol 795. Springer, Cham

[8] Strel'nikova I. V., Strel'nikova G. V. Psihoemocional'noe sostoyanie kibersportsmenov pered sorevnovaniem [Psycho-emotional state of cybersportsmen before the competition]//Voprosy funkcional'noi podgotovki $\mathrm{v}$ sporte vysshih dostizhenii - [Questions of functional training in the sport of higher achievements]. 2013. T. 1., S. 322-324.

[9] Simonova N. A., Petrushkina N. P. Effektivnost' primeneniya netradicionnyh metodov uluchsheniya svoistv nervnoi sistemy u hokkeistov pubertatnogo vozrasta [The effectiveness of non-traditional methods to improve 
the properties of the nervous system in puberty hockey players]//Zdorov'e dlya vseh -[Health for All] . 2015. S. 325-328.

[10] Banyai, F., Griffiths, M.D., Kirly, O. et al. J Gambl Stud (2018). https://doi.org/10.1007/s10899-018-9763-1

[11] Nick Yee. CyberPsychology \& Behavior. Dec 2006. Ahead of print http://doi.org/10.1089/cpb.2006.9.772

[12] Makalatiya A.G. Motivaciya v komp'yuternyh igrah [Computer games motivation] // 3-ya Rossiiskaya konferenciya po ekologicheskoi psihologii (Moskva, 15-17 sentyabrya 2003 g.) - [Proc. 3rd Russian Conference on Environmental Psychology]: tez. M. 2003. S.358-361.

[13]Fomicheva Yu.V., Shmelev A.G., Burmistrov I.V. Psihologicheskie korrelyaty uvlechennosti komp'yuternymi igrami [Psychological correlates of computer games enthusiasm] // Vestnik Moskovskogo universiteta [Moscow University Bulletin]. Seriya 14: Psihologiya. 1991. № 3. S. 27-39.

[14] Yurkov, A.A. Tipologizaciya pol'zovatelei onlain-igr i ih motivaciya [Typology of users of online games and their motivation] / A.A. Yurkov // Znanie. Ponimanie. Umenie - [Knowledge. Understanding. Skill.]. M: MosGU, 2012. №3. S.301-304.

[15] Gogunov, E.N. Psihologiya fizicheskogo vospitaniya i sporta [Psychology of physical education and sport]: Ucheb. posobie dlya stud. vysh. ped. ucheb. zavedenii: / E.N.Gogunov, B.I.Mart'yanova. 2-e izd., dorab. M.: Izdatel'skii centr «Akademiya», 2004. $224 \mathrm{~s}$.

[16] Il'in, E.P. Psihologiya fizicheskogo vospitaniya [Psychology of physical education]: Uchebnik dlya institutov i fakul'tetov fizicheskoi kul'tury: 2-e izd., ispr. i dop. / E.P.Il'in. SPb: RGPU im. A. I. Gercena, 2000. 486 s.

[17] Genov, F. Psihologicheskie osobennosti mobilizacionnoi gotovnosti sportsmena [Psychological features of the mobilization readiness of an athlete]/ F. Genov. M.: Fizkul'tura i sport - [Physical Education and Sport], 1971. $246 \mathrm{~s}$.

[18] Grishina, A.V. Psihologicheskie faktory formirovaniya igrovoi komp'yuternoi zavisimosti v mladshem podrostkovom vozraste [Psychological factors in the formation of computer gaming addiction in the early teens]/ A.V.Grishina // Izvestiya Rossiiskogo gosudarstvennogo pedagogicheskogo universiteta im. A.I. Gercena - [News of the Herzen State University of Russian]. SPb: RGPU im. A. I. Gercena, 2008 g. №88. S. 77-81.

[19] Smoll, G. Mozg onlain: Chelovek v epohu Interneta [Brain Online: Man in the Internet Age] / G, Smoll, G.Vorgan. M.: KoLibri, 2011. 352 s.

[20] Khodakovskaia O.V., Bogdanovskaya I.M., Koroleva N.N., Alekhin A.N., Lugovaya V.F. (2018) Problematic Internet Usage and the Meaning-Based Regulation of Activity Among Adolescents. In: Alexandrov D., Boukhanovsky A., Chugunov A., Kabanov Y., Koltsova O. (eds) Digital Transformation and Global Society. DTGS 2018. Communications in Computer and Information Science, vol 859. Springer, Cham

[21] Chebykina, N.N. Vliyanie komp'yuternyh igr na cheloveka [The impact of computer games on a person] / N.N.Chebykina // Teoriya i praktika professional'nogo obrazovaniya: pedagogicheskii poisk: sbornik nauchnyh trudov - [Theory and practice of vocational education: pedagogical search: a collection of scientific papers]. Ekaterinburg, 2007. - Vyp. 9. S. 193-194.

[22] Strel'nikova G.V., Strel'nikova I.V., Yankin E.L. Osobennosti sensomotornoi i kognitivnoi sfer kibersportsmenov, vystupayushih $\mathrm{v}$ raznyh disciplinah [Features of the sensorimotor and cognitive spheres of cybersportsmen acting in different disciplines]// Nauka i sporta: sovremennye tendencii - [Science and Sports: Current Trends]. Kazan': Povolzhskaya gos. akademiya fizicheskoi kul'tury, sporta i turizma, 2016. T. 12, №3 (12). S. 64-69.

[23] Bogacheva, N.V. Komp'yuternye igry i psihologicheskaya specifika kognitivnoi sfery geimerov [Computer games and the psychological specifics of the cognitive sphere of gamers]/ N.V.Bogacheva // Vestnik Moskovskogo universiteta- [Moscow University Bulletin]. Seriya 14: Psihologiya. M.: Fakul'tet psihologii MGU, 2014. №4. S. 120-130.

[24] Bogacheva, N.V. Psihologiya kibersporta kak novoe napravlenie sportivnoi psihologii [Psychology of eSports as a new direction of sports psychology]/ N.V.Bogacheva, D.V.Smit // Materialy VIII Mezhdunarodnoi nauchno-prakticheskoi konferencii «Rudikovskie chteniya» - [Proc. of the International Scientific and Practical Conference "Rudkov Readings"] (5-7 iyunya 2012 g.). M., 2012. S. 12-15.

[25] Avetisova, A.A. Psihologicheskie osobennosti igrokov v komp'yuternye igry [Psychological features of computer game players] / A.A.Avetisova // Psihologiya. Zhurnal Vysshei shkoly ekonomiki. M.: Nacional'nyi issledovatel'skii universitet «Vysshaya shkola ekonomiki» - [Psychology. Journal of Higher School of Economics], 2011. T. 8, №4. S.35-58.

[26]Lieberman D. A. What Can We Learn From Playing Interactive Games? // Playing video games: motives, responses, and consequences / Ed. by Vorderer P., Bryant J. Mahwah, NJ: LEA Publ.2006. P. 379-398.

[27] Grogoleva O.Yu., Generalova A.V. Psihologicheskii praktikum. Oshushenie. Vospriyatie. Predstavlenie [Psychological workshop. Sensation. Perception. Representation.]: Uchebno-metodicheskoe posobie. Omsk: Omsk. gos. universitet. 2004. 68 s.

[28] Il'in E.P. Psihologiya individual'nyh razlichii [Psychology of individual differences]. Spb: Piter. 2004. 701 s.

[29] Ivannikov V.A., Eidman V.A. Struktura volevyh kachestv po dannym samoocenki. [The structure of volitional qualities according to self-assessment].Psihologicheskii zhurnal - [Psychological Journal]. 1990. T. 11. №3. S.39-40, 